\title{
Apical External Root Resorption and Repair in Orthodontic Tooth Movement: Biological Events
}

\author{
Liviu Feller, ${ }^{1}$ Razia A. G. Khammissa, ${ }^{1}$ George Thomadakis, ${ }^{2}$ \\ Jeanine Fourie, ${ }^{1}$ and Johan Lemmer ${ }^{1}$ \\ ${ }^{1}$ Department of Periodontology and Oral Medicine, Sefako Makgatho Health Sciences University, Pretoria 0204, South Africa \\ ${ }^{2}$ Private Practice, 15 School Road, Corner Rivonia Road, Morningside, Johannesburg, South Africa \\ Correspondence should be addressed to Liviu Feller; liviu.feller@smu.ac.za
}

Received 14 December 2015; Accepted 8 March 2016

Academic Editor: Shinji Kuroda

Copyright (C) 2016 Liviu Feller et al. This is an open access article distributed under the Creative Commons Attribution License, which permits unrestricted use, distribution, and reproduction in any medium, provided the original work is properly cited.

\begin{abstract}
Some degree of external root resorption is a frequent, unpredictable, and unavoidable consequence of orthodontic tooth movement mediated by odontoclasts/cementoclasts originating from circulating precursor cells in the periodontal ligament. Its pathogenesis involves mechanical forces initiating complex interactions between signalling pathways activated by various biological agents. Resorption of cementum is regulated by mechanisms similar to those controlling osteoclastogenesis and bone resorption. Following root resorption there is repair by cellular cementum, but factors mediating the transition from resorption to repair are not clear. In this paper we review some of the biological events associated with orthodontically induced external root resorption.
\end{abstract}

\section{Introduction}

Some apical external root resorption is an invariable side effect of orthodontic treatment. It affects most frequently the maxillary incisors and is associated with several biological and mechanical risk factors (Table 1) [1-11].

It is caused by orthodontic load-induced sterile inflammation that brings about resorption of the superficial root cementum, or it can become more severe with eventual resorption of the underlying dentin [10]. Apical external root resorption is ultimately repaired by cellular cementum but nevertheless may result in permanent loss of root length. Vital and endodontically treated teeth are equally affected [2], regardless of age [9].

Intrinsic factors that may play roles in the pathogenesis of orthodontic load-induced apical external root resorption include polymorphism of genes encoding cytokines and growth factors, alveolar bone density and turnover, hormonal deficiencies, and other local anatomical factors $[4,6,12-16]$.

Reportedly, in about $80 \%$ of subjects, teeth undergoing orthodontic treatment may develop some degree of apical external root resorption [17]. It is almost impossible to establish any reliable estimate of the incidence, prevalence, or degree of severity of orthodontically induced apical external root resorption in terms of either subjects affected or teeth affected, because of differences in the published studies [18]. Studies have used small samples with different types, magnitudes, and durations of applied orthodontic forces. Single rooted and multirooted teeth at different stages of root development have been compared, as have been different orthodontic treatment techniques. Various methodologies with regard to selection criteria of teeth to be included in the studies and of evaluating the root resorption have been applied. Most studies have been retrospective and nonrandomized with orthodontic treatment of different durations, and not all have taken into account systemic or local risk factors [3, 18-21].

Many studies have been carried out on laboratory animals, and the results of such studies, although providing important information on the pathogenic mechanisms of apical external root resorption, cannot be reliably extrapolated to the outcome of treatment of patients [18], nor can studies investigating external root resorption in relation to the number of treated patients be compared to studies investigating the proportion of orthodontically treated teeth which were affected by apical external root resorption [17]. 
TABLE 1: Risk factors-associated with orthodontic treatment-induced apical external root resorption [1-11].

(1) Genetic factors

(2) Systemic factors

(3) Personal susceptibility

(4) Root morphology

(5) Alveolar bone morphology

(6) The magnitude, type (continuous or intermittent), direction and duration of the applied orthodontic force

(7) Type of treatment mechanics (rectangular or round arch wires, springs, elastics, etc)

(8) Nature of tooth movement (intrusion, extrusion, tipping or bodily movement)

(9) Distance of tooth movement

(10) Overall duration of orthodontic treatment

TABLE 2: Classification of degree of external root resorption (based on $[4,7,23,24])$.

\begin{tabular}{ll}
\hline Mild & $\begin{array}{l}\text { Apical root resorption less than } 2 \mathrm{~mm} \text { of the original } \\
\text { root length }\end{array}$ \\
\hline Moderate & $\begin{array}{l}\text { Apical root resorption greater than } 2 \mathrm{~mm} \text { but less } \\
\text { than one-third of the original root length }\end{array}$ \\
\hline Severe & $\begin{array}{l}\text { Root resorption exceeding } 4 \mathrm{~mm} \text { or one-third of the } \\
\text { original root length }\end{array}$ \\
\hline
\end{tabular}

Nevertheless, it is estimated that up to $90 \%$ of orthodontically treated teeth have some degree of apical external root resorption, and up to $15 \%$ of these cases show severe apical resorption of more than $4 \mathrm{~mm}$ (Table 2) $[5,7,17]$. However, in the vast majority of cases, the reduction in root length is slight and clinically insignificant and does not affect the prognosis of the involved teeth [18, 22, 23]. Root resorption that occurs during orthodontic tooth movement ceases at the end of treatment; but in fact, some repair with cellular cementum occurs $[24,25]$.

Since the area of periodontal attachment of a tapering root per millimeter of root length decreases very substantially from the cervical towards the apical region, it is estimated that the loss of periodontal attachment from $3 \mathrm{~mm}$ of apical external root resorption is equivalent to about $1 \mathrm{~mm}$ of cervical bone loss [22]. Indeed, even following severe apical external root resorption of more than $4 \mathrm{~mm}$, the area of periodontal attachment loss is such that the teeth will continue to function normally for many years [24].

Cementum is the thin layer of mineralized tissue at the root surface providing anchorage for the principal fibers of the periodontal ligament $[26,27]$. Cementoblasts, like osteoblasts, express the transcription factors runt-related gene 2 (Runx 2) and osterix which transactivate genes encoding for type 1 collagen, alkaline phosphatase (ALP), bone sialoprotein (BSP), and osteocalcin. It appears that osterix has an important role in regulating the formation of both cellular cementum and bone, by downregulating cell proliferation and upregulating cell differentiation and mineralization [28].

Despite the fact that the differentiation of both cementoblasts and osteoblasts is driven by bone morphogenetic proteins (BMPs), it is unclear whether cementoblasts and osteoblasts are derived from a common mesenchymal multipotential precursor cell [26, 27] or whether cementoblasts originate from an epithelial progenitor cell through epithelial-mesenchymal transition [28] or whether a common cell type mediates the formation of the different subtypes of cementum [29]. In any case it has been suggested that both osteoblasts forming bone and cementoblasts forming cellular cementum arise from a common progenitor cell $[29,30]$.

While in many aspects cementum is similar to bone, cementum differs from bone in having only a limited capacity for remodelling, in lacking innervation, vascularization, or lamellar structure, and in lacking any role in calcium homeostasis or haemopoiesis [19, 26, 30-32]; and the lacunocanalicular network is less developed in cementum than in bone $[29,31]$.

\section{Physiological "Remodelling" of Cementum}

Cementum resorption and subsequent repair by cellular cementum (cementum turnover), which according to some researchers can be regarded as a physiological remodelling process, occurs throughout life in response to metabolic changes in the periodontal ligament mediated by forces of mastication, by continual tooth eruption and drifting, and possibly by parafunctional gnathic activities [10, 32-34]. On the other hand, other researchers are of the opinion that, unlike bone, cementum does not undergo such physiological remodelling but increases in thickness throughout life [30, 35]. Regardless of this debate, external dentin resorption will not occur unless there has been a full-thickness cemental resorption [30, 32, 36, 37].

Resorbed acellular cementum is always repaired with cellular cementum but the molecular pathways and cellular mechanisms which mediate this process are unknown [30, 33]. External root resorption may be induced not only by forces exceeding the physiological limits but also by intrinsic alterations in the $\mathrm{Wnt} / \beta$-catenin and in the receptor activator of nuclear factor $\kappa \beta$ (RANK), RANK ligand (RANKL), and osteoprotegerin (OPG) signalling pathways. Under these circumstances, the extent of the resorption is influenced by the degree of dysregulation of these pathways [12]. 


\section{Apical External Root Resorption during Orthodontic Treatment}

The site of orthodontically mediated resorption on a root surface is determined primarily by whether the tooth is moved bodily or is tipped and occurs predominantly on those parts of the root surfaces exposed to high compressive stresses [11]; but it can also occur, though to a lesser extent, on root surfaces exposed to tensile stresses within the periodontal ligament [19]. The greater the compressive stress is, the greater the root resorption will be [19].

Bodily tooth movement generates compressive stresses along root surfaces with resorption of cementum at zones of compression of the periodontal ligament, but such resorption is less frequent and less severe than the apical root resorption associated with tipping tooth movements [11] because with tipping movements, compressive stresses are concentrated at the thin apical portion of the root where not only is the tooth movement greater, but also the stress per unit surface area is more than that at the much thicker cervical portion of the $\operatorname{root}[19,38,39]$.

Furthermore, the thinner, more elastic alveolar bone around the cervical one-third of the root has the capacity to absorb much more of the orthodontically induced mechanical stress compared to the thick, less elastic alveolar bone that envelops the apical one-third of the root $[8,21,38,39]$.

Orthodontically induced root resorption can be evaluated by conventional radiography, subtraction radiography, conebeam computed tomography, scanning electron microscopy, and histopathology $[11,20]$. Cone-beam computed tomography is the only method that provides three-dimensional information about root resorption in a clinical setting, while periapical or panoramic radiography is two-dimensional and is subject to magnification errors and to low observer reproducibility $[11,40]$. Histopathological examination and scanning electron microscopy are clearly not clinically applicable [11].

In general, in both bodily and tipping tooth movements, external root resorption increases with the magnitude of the applied orthodontic force $[3,14,19,41]$ and with continuous forces $[3,39,42]$, and these factors can be controlled by the type of orthodontic appliance used $[8,39]$. It seems that there is less external root resorption when interrupted or intermittent orthodontic forces are applied because cementum repair can occur in the intervals between force applications $[3,10,33]$.

\section{Resorption of Cementum in the Context of Orthodontic Tooth Movement}

In the context of orthodontic tooth movement, the necrosis and hyalinization in the periodontal ligament and alveolar bone occur in response to localized orthodontic load-induced compression of the vasculature and subsequent ischaemia in the periodontal ligament and adjacent alveolar bone $[19,37$, 43]. Subsequently, removal of necrotic and hyalinized tissues in the compressive zone of the periodontium by macrophagelike cells, multinucleated cells, osteoclasts, and cementoclasts/ odontoclasts has the collateral damaging effect of external root resorption [44-46]. However, it is also possible that direct damage to the superficial layer of the cementum is caused by clast cells-mediated cementum resorption, without necrosis and hyalinization in the periodontal tissues [1].

During load-induced resorption of cementum, it appears that, as in the case of osteoclast differentiation and function [43], a number of biological mediators, including hormones, cytokines, macrophage colony-stimulating factor (M-CSF), and RANK, RANKL, and OPG signalling pathway, play important regulatory roles in the differentiation and function of cementoclasts/odontoclasts [47-49]. The expression of RANKL is upregulated by fibroblasts, osteoblasts, and other resident and transient cells in the compressed periodontal ligament in response to orthodontic loading [49].

Cementoclasts/odontoclasts have a phenotype similar to that of osteoclasts [15], being multinucleated and having ruffled borders, clear zones, abundant mitochondria, rough endoplasmic reticulum, and tartrate-resistant acid phosphatase (TRAP) activity; but in contrast to osteoclasts, the origin of these cells and the molecular pathways that drive their differentiation are not well understood [50, 51]. However, it appears that precursors of cementoclast/odontoclasts originate from circulatory mononuclear cells that extravasate in the periodontal ligament in response to chemotactic agents and then migrate to the areas of resorption on the root surface [51] and that their resorptive activity is also controlled by the RANK/RANKL/OPG signalling pathway expressed in the periodontal ligament [49].

\section{Repair of Cementum in the Context of Orthodontic Tooth Movement}

After the cementoclasts/odontoclasts have become detached from the resorption lacunae, early cementum repair starts with fibroblast-like cells from the periodontal ligament invading the resorption lacunae [44]. These fibroblast-like cementoblastic cells secrete noncollagenous matrix proteins, particularly osteopontin and bone sialoprotein, filling the spaces in the residual collagen fibril structure [44]. Thus, the architecture of the collagen structure determines the pattern of deposition of the noncollagenous proteins [35]. Subsequently, the cementoblasts secrete collagen fibrils that intermingle with the residual fibrils of the existing collagenous structure forming a thin cementoid repair matrix [44-46]. Mineralization ensues with hydroxyapatite crystals development and growth between the collagen fibrils [35], forming reparative cementum of the cellular intrinsic fiber type $[25,44]$.

During this process of cementum repair, extracellular matrix proteins from resorbed cementum including fibronectin, osteopontin, and osteocalcin contribute to the recruitment of cementoblast precursors to the root surface and to their subsequent adhesion, proliferation, and differentiation. Local cytokines and growth factors including insulinlike growth factor- (IGF-) 1, fibroblast growth factor (FGF), epidermal growth factor (EGF), bone morphogenetic proteins (BMPs), and transforming growth factor- $\beta$ (TGF- $\beta$ ) also play important roles in cementoblast precursor differentiation and cementoblast proliferation, further promoting cementogenesis [44]. 
As mentioned previously, epithelial cell rests of Malassez in the periodontal ligament may also play some role in the formation of reparative cementum $[28,52]$. Upregulation of the $\mathrm{Wnt} / \beta$-catenin signalling pathway can promote epithelialmesenchymal transition with dedifferentiation of the epithelial cell rests of Malassez which subsequently differentiate into cementoblast-like mesenchymal cells that can contribute to the formation of reparative cementum $[28,52]$. It is also possible that epithelial cell rests of Malassez promote cementum formation indirectly by secreting inductive signalling mediators [52].

The Wnt/ $\beta$-catenin signalling pathway, in addition to its role in epithelial-mesenchymal transition in the context of cementogenesis, is essential for osteoblast differentiation during embryogenesis and postnatally for regulating osteoblast proliferation. Canonical Wnt/ $\beta$-catenin signalling is characterized by accumulation of $\beta$-catenin in the cytoplasm and subsequently its translocation into the nucleus of both osteoblasts and cementoblasts where it interacts with members of the Lef/Tcf family of transcription factors [53].

Wnt $/ \beta$-catenin signalling is regulated by a balance between agonists of frizzled receptors and LRP 5/6 coreceptors on one hand and several antagonists including Dkks and sclerostin on the other hand [53]. In addition, upregulated levels of $\beta$-catenin in mature osteoblasts may induce the production of osteoprotegerin resulting in inhibition of differentiation and of functional activity of osteoclasts. Thus, the canonical Wnt/ $\beta$-catenin signalling pathway via different vectors plays an essential role in bone turnover and subsequently in the regulation of bone mass [53].

Runx 2 is the master transcription factor that upregulates the genes ALP, collagen type 1, osteocalcin, and osteopontin that mediate osteogenic differentiation [54]. Runx 2 is expressed not only by osteogenic cells, but also by the cells laying down reparative cementum within the resorption lacunae [44]. Osterix is another transcription factor essential for osteogenesis and cementogenesis, and like Runx 2, it positively regulates the expression of genes encoding osteopontin, osteocalcin, and bone sialoprotein and the levels of their encoded proteins $[27,55]$.

In relation to cementogenesis, the activated $\mathrm{Wnt} / \beta$ catenin signalling pathway in cementoblasts inhibits the expression of Runx 2 and osterix, resulting in downregulation of cementoblast differentiation and proliferation [26]. Conversely, downregulation of the $\mathrm{Wnt} / \beta$-catenin signalling pathway is positively associated with differentiation of cementoblasts and subsequent increased formation of cementum [27]. However, other researchers have reported that, on the contrary, upregulation of the $\mathrm{Wnt} / \beta$-catenin signalling is associated with increased cementum formation [56]; but downregulated $\mathrm{Wnt} / \beta$-catenin signalling is associated with increased resorption of cementum [12]. In any event, the modulation of the $\mathrm{Wnt} / \beta$-catenin signalling pathway plays an important role in the differentiation of cementoblasts and in the formation of cementum $[12,57]$.

Osterix is a transcription factor essential for the differentiation of preosteoblasts and precementoblasts into mature osteoblasts and cementoblasts and functions molecularly downstream from Runx 2. By inhibiting the Wnt/ $\beta$-catenin signalling in cementoblasts and osteoblasts, probably via upregulation of DKK1 expression, osterix inhibits osteoblast and cementoblast proliferation $[27,28,53]$.

Sclerostin is a glycoprotein encoded by the SOST gene, expressed by terminally differentiated cells within mineralized matrices, regulating osteoblast and cementoblast proliferation and differentiation, and ultimately playing an important role in bone formation, maturation, and remodelling [29, 58]. Sclerostin is an inhibitor of the canonical Wnt/ $\beta$-catenin signalling pathway and of pathways of several members of BMP family. These pathways are essential for driving the process of commitment and subsequent differentiation of multipotential mesenchymal progenitor cells along the osteoblastic and cementoblastic lineages [29, 31, 59]. Whereas downregulation of sclerostin in osteocytes may cause sclerosteosis, the effect of such downregulation on cementum is unclear [58].

Orthodontic load-generated strains on cementoblast precursors in the periodontal ligament induce Cox- 2 mRNA expression and the synthesis of prostaglandin $\left(\mathrm{PGE}_{2}\right)$. Subsequently, $\mathrm{PGE}_{2}$ may mediate differentiation of cementoblasts and upregulate the expression of genes involved in mineral metabolism, including osteocalcin and alkaline phosphatase [36].

BMPs, members of the transforming growth factor- $\beta$ (TGF- $\beta$ ) superfamily, are found in high concentration in mineralized tissues. BMPs transduce intracellular signals through Smad-dependent molecular pathways and thorough Smad-independent molecular pathways, interacting with various transcription factors and regulating the expression of target genes [60]. BMPs upregulate the expression of Runx 2 and both independently and cooperatively stimulate osteogenic and cementogenic gene expression [55]. The BMP signalling cross-talks with the Wnt/ $\beta$-catenin signalling pathway, and depending on the tissue involved, these pathways may act synergistically or antagonistically [60]. On the other hand, BMPs have the capacity to induce cementogenesis with cementoblast-generated extracellular matrix formation, mineralization, and the regeneration of Sharpey fibers [55, 60, 61].

BMP-2 promotes differentiation of cementoblast progenitor cells into a cementogenic lineage but has little mineralization-inducing effect on mature cementoblasts. Thus, any mineralization-promoting effect of BMP-2 is probably indirect through its interaction with progenitor cells, mediating the increase in the pool of mature cementoblasts $[59,62]$. On the other hand, BMP signalling pathways in cementoblasts have the capacity to downregulate $\mathrm{Wnt} / \beta$-catenin signalling by activating the Wnt/ $\beta$-catenin inhibitors Dkkl and sclerostin $[52,57]$.

\section{Clinical Considerations in relation to Orthodontic Load-Induced External Root Resorption}

As previously mentioned, strategies to minimize external root resorption should include identification of systemic and local risk factors at the stage of treatment planning, limitation of treatment duration, the use of light intermittent forces, and biannual radiographic monitoring in order to detect any 
possible root resorption at the earliest stage [63]. As some degree of apical external root resorption is a frequent and unavoidable complication of orthodontic treatment, during treatment planning, the patient or parent should be warned of this risk.

It appears that if irregularities of root contour indicative of apical external root resorption are not detected within six to nine months of commencement of orthodontic treatment, then it would be unlikely that any significant apical external root resorption will occur, but if any apical external root resorption is observed within six to nine months from the beginning of orthodontic treatment, then there is a high risk of further root resorption $[64,65]$.

If any apical external root resorption is detected, active treatment should be suspended for two to three months, hopefully to prevent further resorption and to allow some healing with cellular cementum. If further resorption is detected after active treatment has been resumed, the orthodontic treatment plan should be modified [6].

\section{Additional Points}

Some degree of load-induced apical external root resorption is a frequent and an unavoidable complication of orthodontic treatment. The process of external root resorption is complex involving interplay between the various molecular signalling pathways that drive the resorption of cementum and dentin by odontoclasts/cementoclasts. The occurrence of such root resorption will be minimized by careful planning, execution of treatment, and radiographic monitoring.

\section{Competing Interests}

The authors declare that they have no competing interests.

\section{References}

[1] N. Brezniak and A. Wasserstein, "Orthodontically induced inflammatory root resorption. Part II: the clinical aspects," Angle Orthodontist, vol. 72, no. 2, pp. 180-184, 2002.

[2] I. Castro, J. Valladares-Neto, and C. Estrela, "Contribution of cone beam computed tomography to the detection of apical root resorption after orthodontic treatment in root-filled and vital teeth," Angle Orthodontist, vol. 85, no. 5, pp. 771-776, 2015.

[3] M. G. Roscoe, J. B. C. Meira, and P. M. Cattaneo, "Association of orthodontic force system and root resorption: a systematic review," American Journal of Orthodontics and Dentofacial Orthopedics, vol. 147, no. 5, pp. 610-626, 2015.

[4] L. Y. Sharab, L. A. Morford, J. Dempsey et al., "Genetic and treatment-related risk factors associated with external apical root resorption (EARR) concurrent with orthodontia," Orthodontics and Craniofacial Research, vol. 18, no. 1, pp. 71-82, 2015.

[5] C. P. R. Mauès, R. R. do Nascimento, and O. D. V. Vilella, "Severe root resorption resulting from orthodontic treatment: prevalence and risk factors," Dental Press Journal of Orthodontics, vol. 20, no. 1, pp. 52-58, 2015.

[6] B. Weltman, K. W. L. Vig, H. W. Fields, S. Shanker, and E. E. Kaizar, "Root resorption associated with orthodontic tooth movement: a systematic review," American Journal of Orthodontics and Dentofacial Orthopedics, vol. 137, no. 4, pp. 462-476, 2010.

[7] L. D. Tieu, H. Saltaji, D. Normando, and C. Flores-Mir, "Radiologically determined orthodontically induced external apical root resorption in incisors after non-surgical orthodontic treatment of class II division 1 malocclusion: a systematic review," Progress in Orthodontics, vol. 15, p. 48, 2014.

[8] A. D. Mirabella and J. Årtun, "Risk factors for apical root resorption of maxillary anterior teeth in adult orthodontic patients," American Journal of Orthodontics and Dentofacial Orthopedics, vol. 108, no. 1, pp. 48-55, 1995.

[9] G. T. Sameshima and P. M. Sinclair, "Predicting and preventing root resorption: part I. Diagnostic factors," American Journal of Orthodontics and Dentofacial Orthopedics, vol. 119, no. 5, pp. 505-510, 2001.

[10] M. Sawicka, R. Bedini, P. M. Wierzbicki, and C. H. Pameijer, "Interrupted orthodontic force results in less root resorption than continuous force in human premolars as measured by microcomputed tomography," Folia Histochemica et Cytobiologica, vol. 52, no. 4, pp. 289-296, 2014.

[11] S. Ajmera, V. Shivanand, and S. V. Ganeshkar, "Volumetric evaluation of root resorption during orthodontic treatment," Journal of Clinical Orthodontics, vol. 48, no. 2, pp. 113-119, 2014.

[12] W. H. Lim, B. Liu, D. J. Hunter, D. Cheng, S.-J. Mah, and J. A. Helms, "Downregulation of Wnt causes root resorption," American Journal of Orthodontics and Dentofacial Orthopedics, vol. 146, no. 3, pp. 337-345, 2014.

[13] C. Verna, M. Dalstra, and B. Melsen, "Bone turnover rate in rats does not influence root resorption induced by orthodontic treatment," European Journal of Orthodontics, vol. 25, no. 4, pp. 359-363, 2003.

[14] A. Paetyangkul, T. Türk, S. Elekdağ-Türk, A. S. Jones, P. Petocz, and M. A. Darendeliler, "Physical properties of root cementum: part 14. The amount of root resorption after force application for 12 weeks on maxillary and mandibular premolars: a microcomputed-tomography study," American Journal of Orthodontics and Dentofacial Orthopedics, vol. 136, no. 4, pp. 492.el-492.e9, 2009.

[15] M. Yoshimatsu, H. Kitaura, Y. Fujimura et al., "Inhibitory effects of IL-12 on experimental tooth movement and root resorption in mice," Archives of Oral Biology, vol. 57, no. 1, pp. 36-43, 2012.

[16] R. A. Al-Qawasmi, J. K. Hartsfield Jr., E. T. Everett et al., "Genetic predisposition to external apical root resorption," American Journal of Orthodontics and Dentofacial Orthopedics, vol. 123, no. 3, pp. 242-252, 2003.

[17] M. Motokawa, T. Sasamoto, M. Kaku et al., "Association between root resorption incident to orthodontic treatment and treatment factors," European Journal of Orthodontics, vol. 34, no. 3, pp. 350-356, 2012.

[18] D. M. Killiany, "Root resorption caused by orthodontic treatment: an evidence-based review of literature," Seminars in Orthodontics, vol. 5, no. 2, pp. 128-133, 1999.

[19] E. Chan and M. A. Darendeliler, "Physical properties of root cementum. Part 7. Extent of root resorption under areas of compression and tension," American Journal of Orthodontics and Dentofacial Orthopedics, vol. 129, no. 4, pp. 504-510, 2006.

[20] K. Nanekrungsan, V. Patanaporn, A. Janhom, and N. Korwanich, "External apical root resorption in maxillary incisors in orthodontic patients: associated factors and radiographic evaluation," Imaging Science in Dentistry, vol. 42, no. 3, pp. 147154, 2012. 
[21] G. R. Segal, P. H. Schiffman, and O. C. Tuncay, "Meta analysis of the treatment-related factors of external apical root resorption," Orthodontics and Craniofacial Research, vol. 7, no. 2, pp. 71-78, 2004.

[22] K. L. Kalkwarf, R. F. Krejci, and Y. C. Pao, "Effect of apical root resorption on periodontal support," The Journal of Prosthetic Dentistry, vol. 56, no. 3, pp. 317-319, 1986.

[23] K. H. Zawawi and G. A. Malki, "Radiographic comparison of apical root resorption after orthodontic treatment between bidimensional and Roth straight-wire techniques," Journal of Orthodontic Science, vol. 3, no. 4, pp. 106-110, 2014.

[24] D. N. Remington, D. R. Joondeph, J. Årtun, R. A. Riedel, and M. K. Chapko, "Long-term evaluation of root resorption occurring during orthodontic treatment," American Journal of Orthodontics and Dentofacial Orthopedics, vol. 96, no. 1, pp. 4346, 1989.

[25] P. Owman-Moll, J. Kurol, and D. Lundgren, "Repair of orthodontically induced root resorption in adolescents," The Angle Orthodontist, vol. 65, no. 6, pp. 403-410, 1995.

[26] E. Nemoto, Y. Koshikawa, S. Kanaya et al., "Wnt signaling inhibits cementoblast differentiation and promotes proliferation," Bone, vol. 44, no. 5, pp. 805-812, 2009.

[27] Z. Cao, R. Liu, H. Zhang et al., "Osterix controls cementoblast differentiation through downregulation of Wnt-signaling via enhancing DKK1 expression," International Journal of Biological Sciences, vol. 11, no. 3, pp. 335-344, 2015.

[28] Z. Cao, H. Zhang, X. Zhou et al., "Genetic evidence for the vital function of osterix in cementogenesis," Journal of Bone and Mineral Research, vol. 27, no. 5, pp. 1080-1092, 2012.

[29] S. D. M. Lehnen, W. Götz, M. Baxmann, and A. Jäger, "Immunohistochemical evidence for sclerostin during cementogenesis in mice," Annals of Anatomy, vol. 194, no. 5, pp. 415-421, 2012.

[30] D. D. Bosshardt, "Are cementoblasts a subpopulation of osteoblasts or a unique phenotype?" Journal of Dental Research, vol. 84, no. 5, pp. 390-406, 2005.

[31] A. Jäger, W. Götz, S. Lossdörfer, and B. Rath-Deschner, "Localization of SOST/sclerostin in cementocytes in vivo and in mineralizing periodontal ligament cells in vitro," Journal of Periodontal Research, vol. 45, no. 2, pp. 246-254, 2010.

[32] X. Bao, X. Liu, Y. Zhang, Y. Cui, J. Yao, and M. Hu, "Strontium promotes cementoblasts differentiation through inhibiting sclerostin expression in vitro," BioMed Research International, vol. 2014, Article ID 487535, 8 pages, 2014.

[33] W. E. Roberts, J. A. Roberts, B. N. Epker, D. B. Burr, and J. K. Hartsfield Jr., "Remodeling of mineralized tissues, part I: the frost legacy," Seminars in Orthodontics, vol. 12, no. 4, pp. 216237, 2006.

[34] S. Deane, A. S. Jones, P. Petocz, and M. A. Darendeliler, "Physical properties of root cementum. Part 12. The incidence of physiologic root resorption on unerupted third molars and its comparison with orthodontically treated premolars: a microcomputed-tomography study," American Journal of Orthodontics and Dentofacial Orthopedics, vol. 136, no. 2, pp. 148.e1-148.e9, 2009.

[35] D. D. Bosshardt, S. Zalzal, M. D. Mckee, and A. Nanci, "Developmental appearance and distribution of bone sialoprotein and osteopontin in human and rat cementum," Anatomical Record, vol. 250, no. 1, pp. 13-33, 1998.

[36] E. B. Rego, T. Inubushi, A. Kawazoe et al., "Effect of $\mathrm{PGE}_{2}$ induced by compressive and tensile stresses on cementoblast differentiation in vitro," Archives of Oral Biology, vol. 56, no. 11, pp. 1238-1246, 2011.
[37] N. Brezniak and A. Wasserstein, "Orthodontically induced inflammatory root resorption. Part I: the basic science aspects," Angle Orthodontist, vol. 72, no. 2, pp. 175-179, 2002.

[38] A. Consolaro, "Force distribution is more important than its intensity!, Dental Press Journal of Orthodontics, vol. 19, no. 1, pp. 5-7, 2014.

[39] O. A. Cuoghi, C. A. Aiello, A. Consolaro, P. M. Tondelli, and M. R. D. Mendonça, "Resorption of roots of different dimension induced by different types of forces," Brazilian Oral Research, vol. 28, no. 1, 2014.

[40] N. P. da Silva, F. I. Suano de Souza, A. I. Pendezza et al., "Homocysteine and cysteine levels in prepubertal children: association with waist circumference and lipid profile," Nutrition, vol. 29, no. 1, pp. 166-171, 2013.

[41] T. Nakano, H. Hotokezaka, M. Hashimoto et al., "Effects of different types of tooth movement and force magnitudes on the amount of tooth movement and root resorption in rats," Angle Orthodontist, vol. 84, no. 6, pp. 1079-1085, 2014.

[42] T. Kumasako-Haga, T. Konoo, K. Yamaguchi, and H. Hayashi, "Effect of 8-hour intermittent orthodontic force on osteoclasts and root resorption," American Journal of Orthodontics and Dentofacial Orthopedics, vol. 135, no. 3, pp. 278.e1-278.e8, 278279, 2009.

[43] L. Feller, R. A. G. Khammissa, I. Schechter, A. Moodley, G. Thomadakis, and J. Lemmer, "Periodontal biological events associated with orthodontic tooth movement: the biomechanics of the cytoskeleton and the extracellular matrix," Scientific World Journal, vol. 2015, Article ID 894123, 7 pages, 2015.

[44] A. Jäger, D. Kunert, T. Friesen, D. Zhang, S. Lossdörfer, and W. Götz, "Cellular and extracellular factors in early root resorption repair in the rat," European Journal of Orthodontics, vol. 30, no. 4, pp. 336-345, 2008.

[45] P. Brudvik and P. Rygh, "Transition and determinants of orthodontic root resorption-repair sequence," European Journal of Orthodontics, vol. 17, no. 3, pp. 177-188, 1995.

[46] P. Brudvik and P. Rygh, "The repair of orthodontic root resorption: an ultrastructural study," European Journal of Orthodontics, vol. 17, no. 3, pp. 189-198, 1995.

[47] Y. Nakano, M. Yamaguchi, S. Fujita, M. Asano, K. Saito, and K. Kasai, "Expressions of RANKL/RANK and M-CSF/c-fms in root resorption lacunae in rat molar by heavy orthodontic force," European Journal of Orthodontics, vol. 33, no. 4, pp. 335343, 2011.

[48] Z. Hakami, H. Kitaura, K. Kimura et al., "Effect of interleukin4 on orthodontic tooth movement and associated root resorption," European Journal of Orthodontics, vol. 37, no. 1, pp. 87-94, 2015.

[49] J. B. Tyrovola, M. N. Spyropoulos, M. Makou, and D. Perrea, "Root resorption and the OPG/RANKL/RANK system: a mini review," Journal of Oral Science, vol. 50, no. 4, pp. 367-376, 2008.

[50] T. Sasaki, "Differentiation and functions of osteoclasts and odontoclasts in mineralized tissue resorption," Microscopy Research and Technique, vol. 61, no. 6, pp. 483-495, 2003.

[51] R. Kimura, H. Anan, A. Matsumoto, D. Noda, and K. Maeda, "Dental root resorption and repair: histology and histometry during physiological drift of rat molars," Journal of Periodontal Research, vol. 38, no. 5, pp. 525-532, 2003.

[52] Z. Yang, B. Hai, L. Qin et al., "Cessation of epithelial Bmp signaling switches the differentiation of crown epithelia to the root lineage in a $\beta$-catenin-dependent manner," Molecular and Cellular Biology, vol. 33, no. 23, pp. 4732-4744, 2013. 
[53] C. Zhang, K. Cho, Y. Huang et al., "Inhibition of Wnt signaling by the osteoblast-specific transcription factor Osterix," Proceedings of the National Academy of Sciences of the United States of America, vol. 105, no. 19, pp. 6936-6941, 2008.

[54] P. Zhang, Y. Wu, Z. Jiang, L. Jiang, and B. Fang, "Osteogenic response of mesenchymal stem cells to continuous mechanical strain is dependent on ERK1/2-Runx2 signaling," International Journal of Molecular Medicine, vol. 29, no. 6, pp. 1083-1089, 2012.

[55] S. S. Hakki, B. L. Foster, K. J. Nagatomo et al., "Bone morphogenetic protein-7 enhances cementoblast function in vitro," Journal of Periodontology, vol. 81, no. 11, pp. 1663-1674, 2010.

[56] U. Kuchler, U. Y. Schwarze, T. Dobsak et al., "Dental and periodontal phenotype in sclerostin knockout mice," International Journal of Oral Science, vol. 6, no. 2, pp. 70-76, 2014.

[57] C. H. Bae, J. Y. Lee, T. H. Kim et al., "Excessive Wnt/ $\beta$-catenin signaling disturbs tooth-root formation," Journal of Periodontal Research, vol. 48, no. 4, pp. 405-410, 2013.

[58] R. L. van Bezooijen, A. L. Bronckers, R. A. Gortzak et al., "Sclerostin in mineralized matrices and van buchem disease," Journal of Dental Research, vol. 88, no. 6, pp. 569-574, 2009.

[59] M. Zhao, G. Xiao, J. E. Berry, R. T. Franceschi, A. Reddi, and M. J. Somerman, "Bone morphogenetic protein 2 induces dental follicle cells to differentiate toward a cementoblast/osteoblast phenotype," Journal of Bone and Mineral Research, vol. 17, no. 8, pp. 1441-1451, 2002.

[60] K. Miyazono, S. Maeda, and T. Imamura, "BMP receptor signaling: transcriptional targets, regulation of signals, and signaling cross-talk," Cytokine and Growth Factor Reviews, vol. 16, no. 3, pp. 251-263, 2005.

[61] U. Ripamonti, J. Teare, and J.-C. Petit, "Pleiotropism of bone morphogenetic proteins: from bone induction to cementogenesis and periodontal ligament regeneration," Journal of the International Academy of Periodontology, vol. 8, no. 1, pp. 2332, 2006.

[62] M. Zhao, J. E. Berry, and M. J. Somerman, "Bone morphogenetic protein-2 inhibits differentiation and mineralization of cementoblasts in vitro," Journal of Dental Research, vol. 82, no. 1, pp. 23-27, 2003.

[63] E. Lim, D. Belton, P. Petocz, M. Arora, L. L. Cheng, and M. A. Darendeliler, "Physical properties of root cementum: part 15. Analysis of elemental composition by using proton-induced $\mathrm{X}$-ray and gamma-ray emissions in orthodontically induced root resorption craters of rat molar cementum after exposure to systemic fluoride," American Journal of Orthodontics and Dentofacial Orthopedics, vol. 139, no. 2, pp. e193-e202, 2011.

[64] N. Brezniak and A. Wasserstein, "Root resorption after orthodontic treatment: part 2. Literature review," American Journal of Orthodontics and Dentofacial Orthopedics, vol. 103, no. 2, pp. 138-146, 1993.

[65] E. Levander and O. Malmgren, "Evaluation of the risk of root resorption during orthodontic treatment: a study of upper incisors," European Journal of Orthodontics, vol. 10, no. 1, pp. 3038, 1988. 

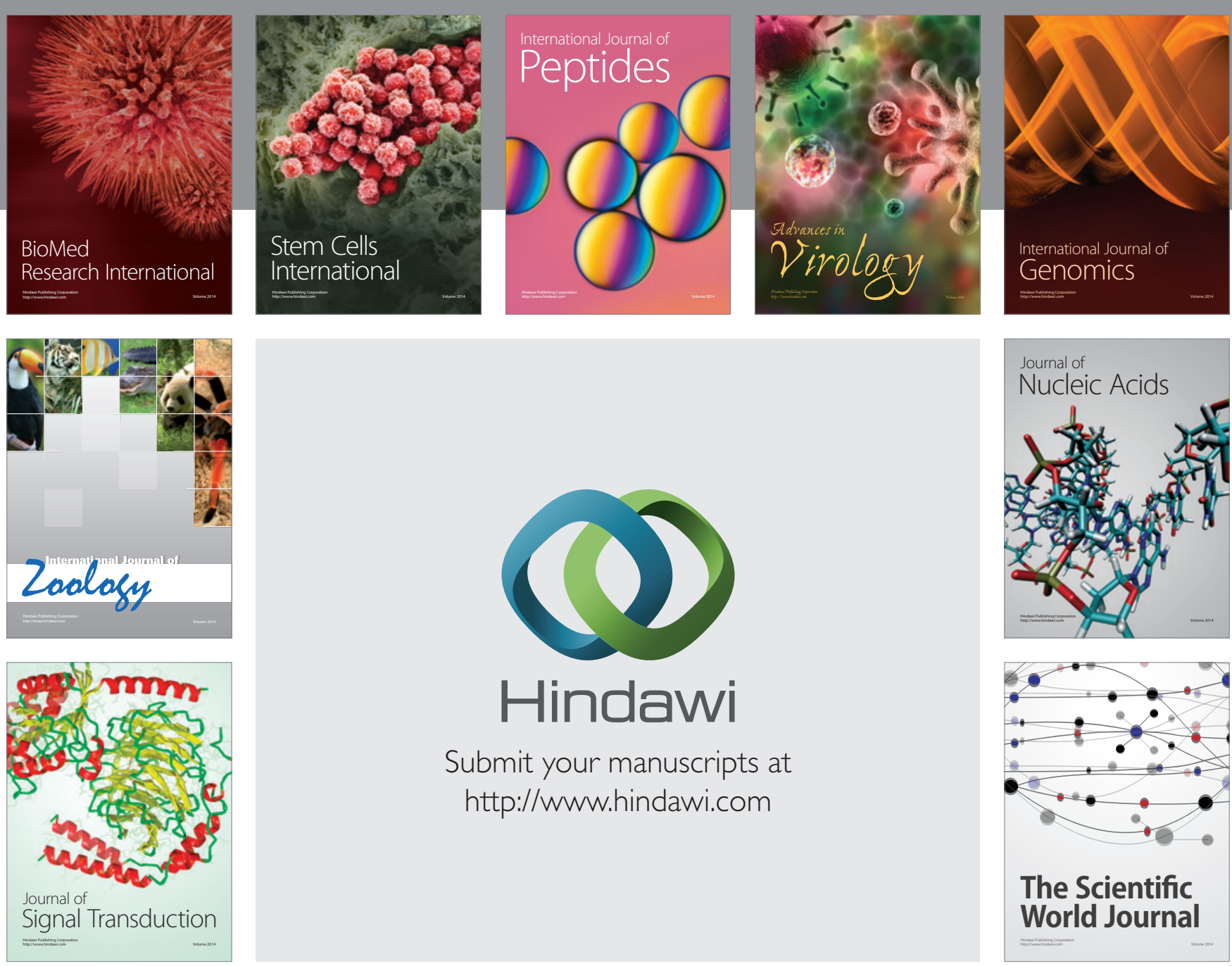

Submit your manuscripts at

http://www.hindawi.com
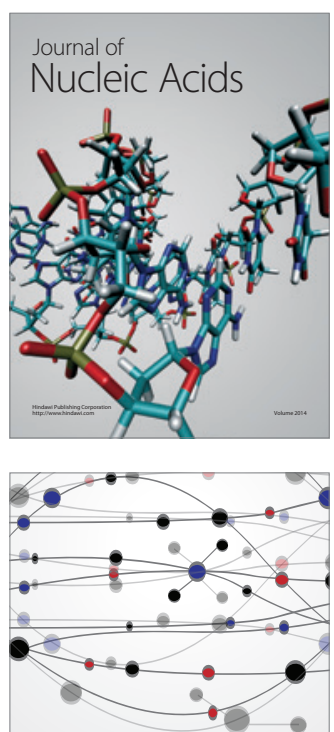

The Scientific World Journal
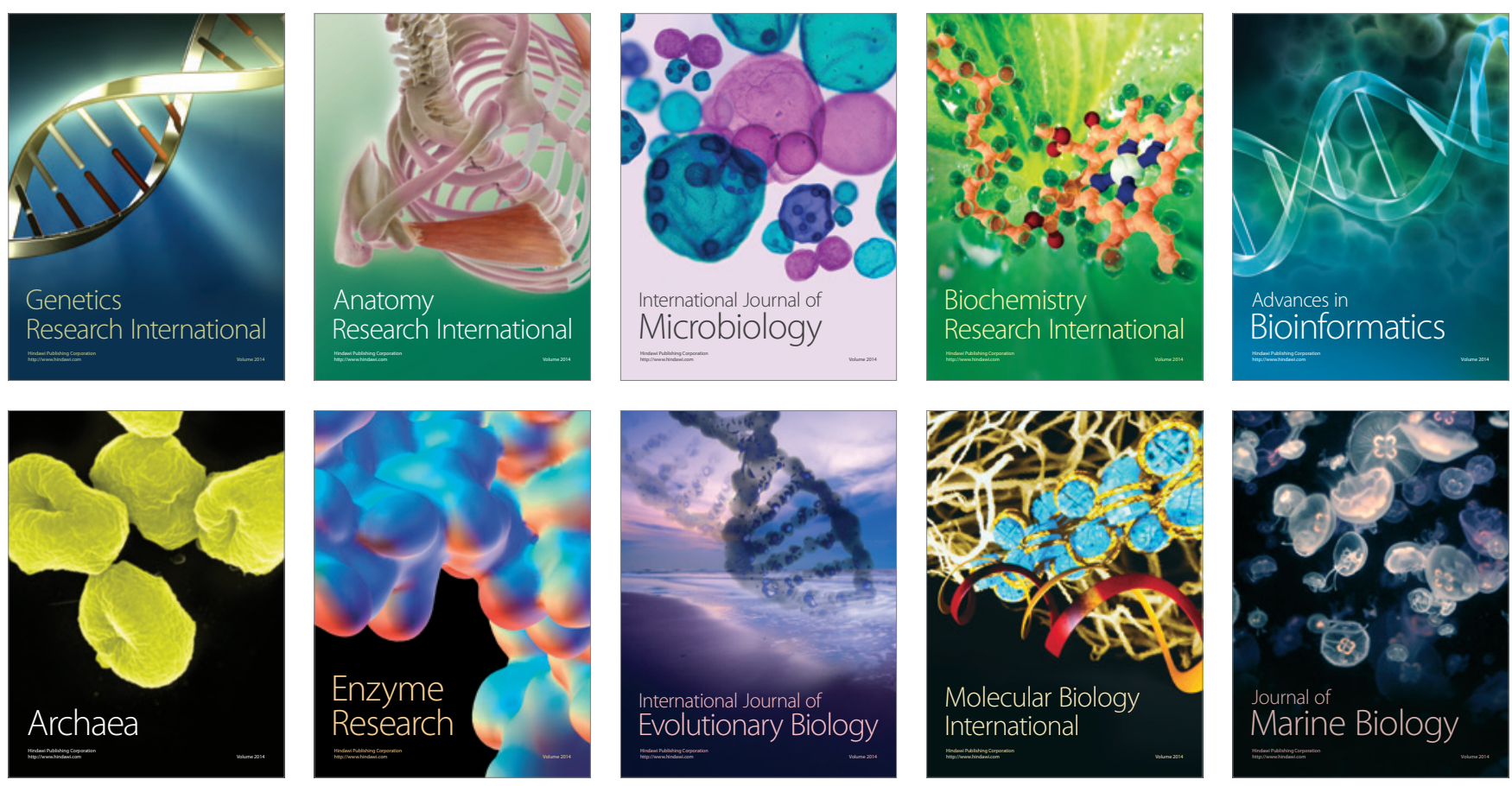